\title{
Management of Charging Load of Electric Vehicles for Optimal Capacity Utilisation of Distribution Transformers
}

\author{
Rilwan Olaolu Oliyide1,2, Liana M. Cipcigan² \\ ${ }^{1}$ Department of Electrical/Electronic Engineering, Moshood Abiola Polytechnic, Abeokuta, Nigeria \\ ${ }^{2}$ Institute of Energy, School of Engineering, Cardiff University, Cardiff, UK \\ Email: oliyide.rilwan@mapoly.edu.ng, CipciganLM@cardiff.ac.uk
}

How to cite this paper: Oliyide, R.O. and Cipcigan, L.M. (2021) Management of Charging Load of Electric Vehicles for Optimal Capacity Utilisation of Distribution Transformers. Journal of Power and Energy Engineering, 9, 60-79.

https://doi.org/10.4236/jpee.2021.911004

Received: October 7, 2021

Accepted: November 27, 2021

Published: November 30, 2021

Copyright $\odot 2021$ by author(s) and Scientific Research Publishing Inc. This work is licensed under the Creative Commons Attribution International License (CC BY 4.0).

http://creativecommons.org/licenses/by/4.0/ (c) (i) Open Access

\begin{abstract}
A de-centralised load management technique exploiting the flexibility in the charging of Electric Vehicles (EVs) is presented. Two charging regimes are assumed. The Controlled Charging Regime (CCR) between 16:30 hours and 06:00 hours of the next day and the Uncontrolled Charging Regime (UCR) between 06:00 hours and 16:30 hours of the same day. During the CCR, the charging of EVs is coordinated and controlled by means of a wireless two-way communication link between EV Smart Charge Controllers (EVSCCs) at EV owners' premises and the EV Load Controller (EVLC) at the local LV distribution substation. The EVLC sorts the EVs batteries in ascending order of their states of charge (SoC) and sends command signals for charging to as many EVs as the transformer could allow at that interval based on the condition of the transformer as analysed by the Distribution Transformer Monitor (DTM). A real and typical urban LV area distribution network in Great Britain (GB) is used as the case study. The technique is applied on the LV area when its transformer is carrying the future load demand of the area on a typical winter weekday in the year 2050 . To achieve the load management, load demand of the LV area network is decomposed into Non-EV load and EV load. The load on the transformer is managed by varying the EV load in an optimisation objective function which maximises the capacity utilisation of the transformer subject to operational constraints and non-disruption of daily trips of EV owners. Results show that with the proposed load management technique, LV distribution networks could accommodate high uptake of EVs without compromising the useful normal life expectancy of distribution transformers before the need for capacity reinforcement.
\end{abstract}




\section{Keywords}

Electric Vehicles, Load Management, EV Charge Controller, EV Load

Controller, Distribution Transformer Monitor

\section{Introduction}

The uptake of low carbon technologies (LCTs), particularly Electric Vehicles (EVs) and Heat Pumps (HPs), at low voltage (LV) distribution networks, in the quest of cutting down on greenhouse gas (GHG) emissions in the transportation and residential sectors, has the potential to cause general load increase and may lead to higher and longer peak load demand [1] [2]. This development can, as indicated in previous studies [2] [3], pose a real challenge of capacity overloading to transformers at LV distribution networks of electricity system.

Transformer is one of the most critical equipment in the power system [4]. Although, transformers are usually designed to withstand certain margin of overload, prolonged periods of transformer overloading could lead to premature transformer failure and shorten transformer's normal useful life expectancy [5]. Amongst the impacts of an unplanned outage of a transformer are reduction in system reliability and economic losses to Distribution Network Operators (DNOs) [6] [7].

Traditional solution to addressing distribution transformers overloading due to widespread and high uptake of EVs and HPs would have been upgrading of transformer capacity. However, the number of LV distribution transformers in electricity system to be upgraded, the logistic, and the resources involved for such operation, and in many cases the seasonal nature of the overloads make the solution less desirable to the DNOs [2] [8].

Therefore, alternative smart solution must be the approach. Conclusions from the study completed on behalf of all DNOs in GB, called DS2030, and reported in [9], showed that with suitable adaptation (smart and traditional) the future power network would be technically viable and capable of serving consumers in line with the national standards for security and quality that are applied today.

In previous literature, many methods have been proposed for managing EVs and HPs load without overloading the transformer. A number of strategies to minimise domestic peak demand by controlling charging of EVs and operation of HPs and consequently mitigate their impacts on LV distribution network were proposed in [10]. The strategies include load shifting, demand limited charging and heating, fast and slow charging and bi-directional EV battery operation. The most successful strategy according to [10] was a combination of bi-directional EV battery operation and demand limited heating and charging. However, the degradation of EV batteries and its economic implications in bi-directional operation were not considered.

An investigative experiment into the degradation impacts of bidirectional op- 
eration of commercial Li-ion cells, similar to the EV batteries, was presented in [11]. Results of the experiment showed that a bi-directional operation once a day accelerates both the capacity loss and resistance increase of the battery and could decrease the lifetime of the battery to under 5 years.

In [12], the smooth integration of EVs and management of their charging load in distribution network was based on the coordinated interactions of four agents demonstrated in a multi-agent system (MAS) based software programs. The four agents according to [12] are:

1) EV agents who are the EV owners whose requirements of daily trip schedules and daily charge needs must be satisfied.

2) EV virtual power plant agents who are responsible for managing the EVs charging process and guarantee the daily trip schedules of EV owners in the face of power system requirements and constraints.

3) Distribution system operator technical agent who is responsible for congestion verification after obtaining charging requirements and schedules from the EV virtual power plant agents.

4) Distribution system operator market agent who is responsible for establishing the congestion price using market-based control method.

Same approach in [12] of managing congestion in the LV distribution network was described in [3]. In [3], an agent called fleet operator performs similar roles as EV virtual power plant operator in [12]. The low point of the MAS described in [3] and [12] is that the interactions and the flow of communication messages between the agents to ensure their coordination are rather complex with huge computational burden.

A web-based day ahead charge scheduling of EVs was proposed in [13] to manage the overloading problem in the LV network. In the proposed method, a price responsive schedule for EVs which calculates distribution locational marginal price (DLMP) was developed based on the previously received travel plan information of EV owners. The DLMP is high during overloading and low during period of low demand [13]. The DLMP information is then shared with EV owners for them to decide on most economic charging slots. The shortcoming of the approach is that it is prone to uncertainties such as change in EV owners' travel plan and real-time traffic. Also, some EV owners might not be willing to divulge information about their travel plans, which they consider as personal security information.

In this paper, a de-centralised load management technique, which proffers solution to the issue of distribution transformer overloading in LV area distribution networks hosting considerable number of EVs and HPs, is presented. The proposed de-centralised load management technique exploits the flexibility in the charging of EVs, by taking advantage of long periods of EVs parking, to coordinate and control their charging without disrupting normal daily trips of EV owners or violating operational limits of the network.

In the proposed load management technique, two charging regimes are introduced: 
1) Controlled Charging Regime (CCR)-This is between 16:30 hours and 06:00 hours of the next day. Within this period, the charging of EVs is coordinated and controlled by means of a wireless two-way communication link between EV Smart Charge Controllers (EVSCCs) at EV owners' premises and the EV Load Controller (EVLC) at the local LV distribution substation. The system aims at meeting the daily charge energy requirement of all the EVs in the LV area within this period without thermally overloading the transformer or violating any operational constraint. The process involves sorting the connected EVs according to their batteries' state of charge (SoC) and determining the number of EVs that could be placed on the network for charging during a time interval based on their SoC and network constraints including thermal limit of the transformer.

2) Uncontrolled Charging Regime (UCR) - This is between 06:00 hours and 16:30 hours of the same day. In this period the charging of EVs is not coordinated.

The usefulness of the proposed load management technique is shown in a case study of a real and typical urban LV area distribution network in Great Britain (GB) when its transformer is carrying the future load demand of the area on a typical winter weekday in the year 2050.

The proposed load management technique avoids the shortcomings identified in previous literature. Thus, the proposed load management technique requires no travel plan information from EV owners. It avoids bi-directional operation of EV batteries. It also avoids complex interactions and information flow between agents.

The rest of the paper is organized as follows: Section 2 describes the daily commuting patterns in the UK. This section highlights the flexibility potential in the coordinated and controlled charging of EVs due to long period of parking at homes. In Section 3, the architecture of the proposed load management technique is presented. The mathematical design and algorithm development for the proposed load management technique are presented in Section 4. Details of the real LV network used as the case study are presented in Section 5 . The proposed method is implemented on the case study in Section 6. Results are presented and discussed in Section 7 and in Section 8 summary and conclusions are drawn.

\section{Daily Commuting Patterns and EVs Use}

Understanding the timing and duration of EVs availability for charging, which is a function of the EV owners' daily trips patterns, would help DNOs to make cost-effective infrastructure and operational decisions. Amongst the key observations from [14] indicated that most EV owners are either full time employed or self-employed and most EV owners charge at home. Therefore, understanding the daily commuting patterns of $\mathrm{EV}$ owners is crucial for proper design and implementation of the proposed controlled charging technique. According to [15], average start time of "outbound" commuting journeys is 07:51 hours and 
the average start time of "homebound" commuting journey is 16:23 hours.

Figure 1 shows the daily trip patterns of commuters (percentage of commuters on the primary y-axis) between the year 1998 and 2014 (on the secondary y-axis) from the National Travel Survey as reported in [15]. From the UK Time Use Survey (UKTUS) data set [16], an average of 88 minutes (1.5 hrs) is spent on daily trips out of total 1440 minutes ( $24 \mathrm{hrs}$ ) while the average time spent sleeping and resting is 517 minutes $(8.6 \mathrm{hrs})$. Therefore, it can be implied from the foregoing that an EV would be parked at home for at least eight hours. Also, the probability of the parking period falling between 16:23 hours to 07:51 hours of the next day is high-more than $70 \%$ as seen in Figure 1.

\section{The Architecture of the De-Centralised Load Management Technique}

Figure 2 shows the architecture of the proposed load management. The principal components of the architecture are EVSCCs located at the EV Owners' homes, the EVLC located at the LV distribution substation and the Distribution Transformer Monitor (DTM) also located at the LV substation. The DTM is a special hardware device that collects, measures, records and processes key parameters of the distribution transformer such as load currents, temperature, oil level and the voltage [17] [18] [19]. The DTM is the interface device between the EVLC and the distribution transformer.

The EVs are connected to the EVSCC for charging process to begin. The EVSCCs read the SoC of the batteries of the connected EVs, send their readings to the EVLC and await the control signal. The EVLC sorts the SoC in ascending

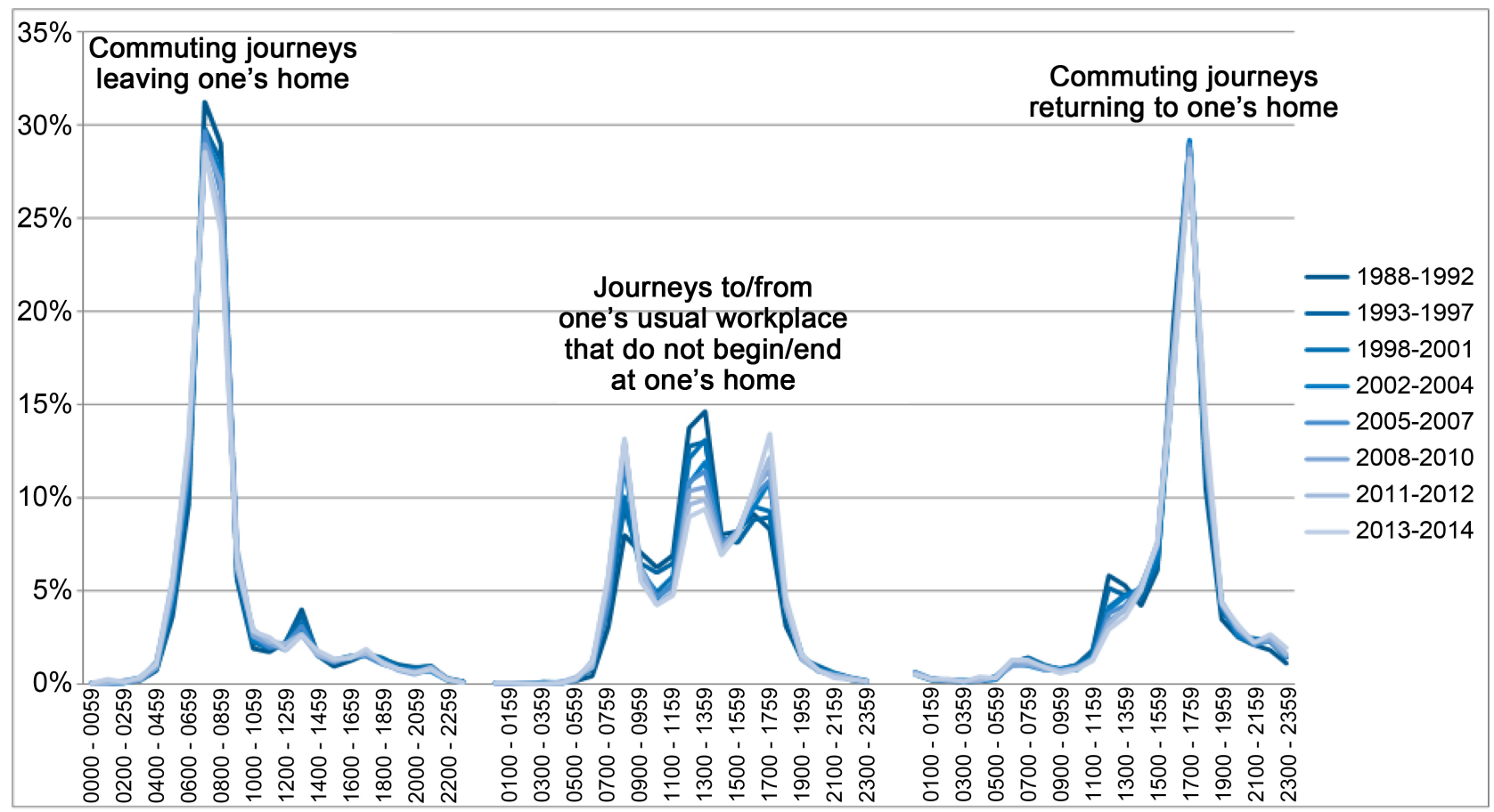

Figure 1. Daily trip patterns of commuters (National Travel Survey) as reported in [15]. 


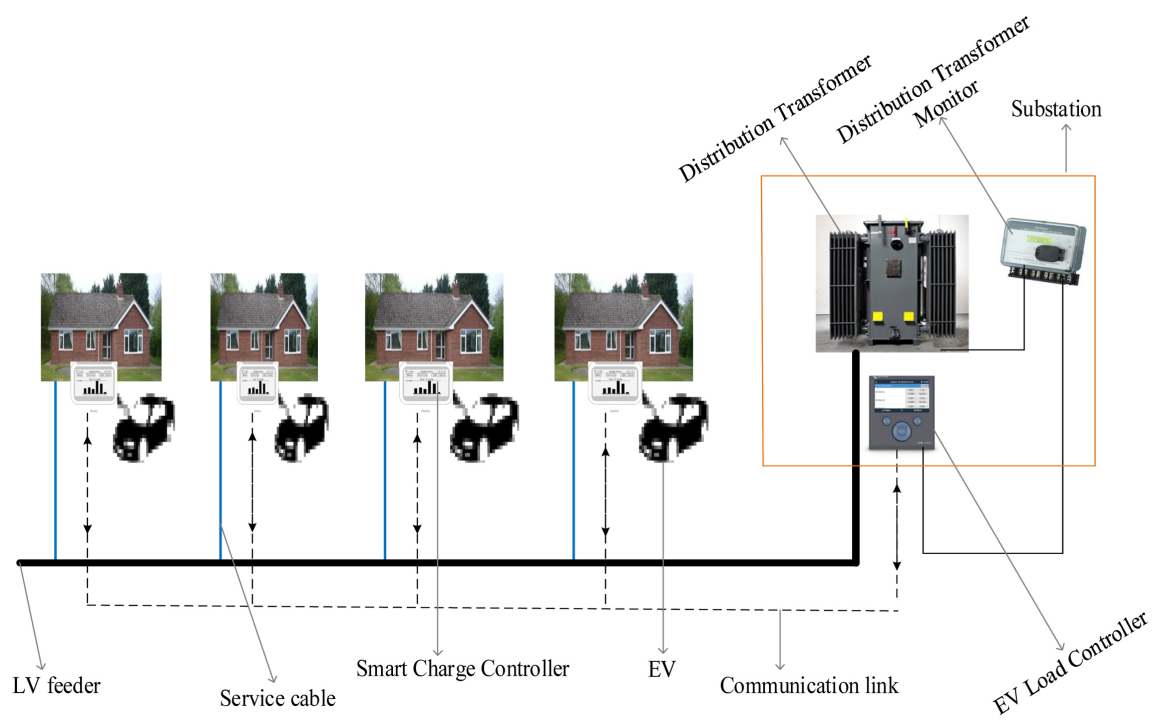

Figure 2. The architecture of the load management.

order, calculates the charge energy and checks the DTM if the transformer can accommodate all the EVs at that period without violating any operational constraints, for example, thermal limits of the transformer and feeders, voltage deviation limits, etc.

If the transformer can accommodate all the EVs at that period, a "YES" control signal is sent to each of the EVSCCs to commence charging. But in the event that the transformer can only accommodate some but not all the EVs, the EVLC determines the number of EVs to be sent a "YES" control signal (i.e., the number of EVs to be charged) through their EVSCCs giving priority to EVs with low SoC. The process is repeated at the next time interval. The cycle continues until all the connected EVs are fully charged. It is important to mention that the process described above is only operational during the period of CCR but not during the period of UCR.

The two-way communication links between the EVSCCs and EVLC could be implemented either through Wireless Mesh Network (WMN) or WiMAX (Worldwide Interoperability for Microwave Access). Both WMN and WiMAX are not expensive, easy to implement and capable of wireless coverage reach of large area [20] [21] [22].

The uniqueness of this architecture is that it offers a de-centralised and autonomous system of EV charge management at the LV distribution network level devoid of complex interactions and exchange of information between EV owners, EV load aggregators and the DNOs.

\section{The Design Formulation}

The objective of the proposed load management is to ensure that the distribution transformer is able to meet, at all times, the load demand of the LV area it is serving without violating any operational constraint or affecting the normal activities of the residents of the $\mathrm{LV}$ area. 
Firstly, to achieve the objective, the load on the transformer at a time interval $t$ is broken into two components:

- Non-EV load-all other domestic loads excluding EVs charging load.

- EV load-exclusively EVs charging load.

Then, the transformer load is modulated by varying the EV load in an optimisation objective function which aims at maximising the transformer capacity utilisation subject to operational constraints and non-disruption of normal daily trips of EV owners in the LV area. This can be expressed mathematically as in Equation (1).

$$
L_{(t)}=\max \sum_{t=1}^{T}\left[L_{\text {nonEV }(t)}+P_{c h g} \sum_{i=1}^{N} E V_{i(t)}\right]
$$

where:

$L_{(t)}$ is the load (kW) on transformer at time interval $t$.

$L_{\text {nonEV }(t)}$ is the Non-EV load $(\mathrm{kW})$ at time interval $t$.

$P_{c h g}$ is the charger power rating $(\mathrm{kW})$.

$E V$ is the Electric Vehicle as an entity.

$t$ is the index of time interval.

$T$ is the total number of time intervals covering the CCR period.

$i$ is the identifier index for EVs.

$N$ is the total number of EVs.

The optimisation objective function of Equation (1) is subject to the following constraints:

$$
\begin{gathered}
L_{\text {nonEV }(t)} \geq L_{\text {nonEV }} \text { frecassed }(t) \\
P_{\text {chg }} \sum_{t=1}^{T} \sum_{i=1}^{N} E V_{i(t)} \geq P_{\text {battery }} \sum_{i=1}^{N}\left(1-\operatorname{SoC}_{i_{\text {initial }}}\right) \\
\operatorname{SoC}_{i_{\text {initial }}} \geq 0.3 \\
L_{(t)} \leq \operatorname{Tr} x_{\text {limit }(t)}
\end{gathered}
$$

where:

$L_{\text {nonEV }}^{\text {forecasted }(t)}$ is the forecasted domestic load $(\mathrm{kW})$ at time interval $t$.

$L_{\text {nonEV }(t)}$ is the actual Non-EV (domestic) load (kW) at time interval $t$.

$P_{c h g}$ is the charger power rating $(\mathrm{kW})$.

$E V$ is the Electric Vehicle as an entity.

$P_{\text {battery }}$ is the battery power rating $(\mathrm{kW})$ of EV.

$S o C_{i_{\text {initial }}}$ is the SoC (\%) of the battery of $E V_{i}$ at the time of plugging in.

$L_{(t)}$ is the load $(\mathrm{kW})$ on transformer at time interval $t$.

$\operatorname{Tr} x_{\text {limit }(t)}$ is the transformer thermal load limit at timeinterval $t$.

$t$ is the index of time interval.

$T$ is the total number of time intervals covering the CCR period.

$i$ is the identifier index for EVs.

$N$ is the total number of EVs.

The constraint expressed in Equation (2) ensures that the domestic (non-EV) 
load of the LV area is always met even when the load forecast is by mistake less than the actual. Equation (3) aims at ensuring that the daily charge requirements of all connected EVs are met (i.e. the SoC of EVs are restored back to $100 \%$ before the start of the next day's trips) within the period of the CCR. In Equation (3), it is assumed that the EVs are connected for charging via a Mode 3 (AC) dedicated EV charging system operating at $3.7 \mathrm{~kW}(16 \mathrm{~A})$ as defined by BS EN 61851-1 standards [23]. Mode 3 charging system is capable of smart charging and it incorporates control, communications and protection functions [24].

In Equation (4), it is assumed that the initial SoC of EV batteries at the time of connection is limited to a minimum of $30 \%$. The reason for this assumption is because 2015 Nissan Leaf $24 \mathrm{kWh}$ model is chosen as the representative EV. Nissan Leaf is the most popular pure electric car in the UK [25]. 2015 Nissan Leaf $24 \mathrm{kWh}$ has a combined city and highway efficiency of approximately 0.2 $\mathrm{kWh} / \mathrm{km}$ and a range of at least $120 \mathrm{~km}$ on full battery charge [26]. From the National Travel Survey [27], average daily car travel distance in the UK is estimated to be $36 \mathrm{~km}$. Therefore, with EV efficiency and average daily car travel distance already established, an EV will need $7.2 \mathrm{kWh}$, which is $30 \%$ of the full $\mathrm{SoC}$ of the battery, as its average daily energy requirement. It is therefore expected that EV owners should not deplete their batteries SoC below the minimum required to guarantee the daily average travelled distance.

The constraint of Equation (5) is to ensure that the transformer is not at any time loaded beyond its limit. The limit in this context refers to the adaptive thermal limit (ATL) of the transformer that ensures optimal capacity utilisation under the real and present conditions without compromising the full useful life of the transformer. The ATL of the transformer at time interval $t$ is determined by the following conditions according to IEC 60076-7:2005 standard [28]:

$$
\begin{gathered}
K(t)=\frac{L_{(t)}}{L_{(R)}} \leq 1.8 \\
\Delta \operatorname{TOR}(t)=\Delta \operatorname{TOR}_{(R)} \times\left(\frac{\left(K_{(t)}^{2} \times R\right)+1}{R+1}\right) x \leq 110^{\circ} \mathrm{C} \\
\operatorname{HST}(t)=T_{a}(t)+\Delta \operatorname{TOR}(t)+\Delta H S T O G(t) \leq 140^{\circ} \mathrm{C} \\
\operatorname{LoL}_{(24 h r)}=\frac{\sum_{t=1}^{T}\left(A A F(t) \times T_{s}(t)\right)}{\sum_{t=1}^{T} T_{s}(t)} \times \frac{24}{N_{\text {life }}} \times 100 \% \leq 0.0133 \%
\end{gathered}
$$

where:

$K(t)$ is the ratio of the load $\left(L_{(t)}\right)$ on the transformer at timeinterval $t$ to the rated load $\left(L_{(R)}\right)$ of the transformer.

$\triangle T O R(t)$ is the top-oil temperature rise $\left({ }^{\circ} \mathrm{C}\right)$ of the transformer at time interval $t$.

$\Delta T O R_{(R)}$ is the top-oil temperature rise $\left({ }^{\circ} \mathrm{C}\right)$ at rated load.

$R$ is the ratio of loss at rated load to no-load loss.

$x$ is the oil exponent constant of the transformer. 
$\operatorname{HST}(t)$ is the Hot Spot Temperature $\left({ }^{\circ} \mathrm{C}\right)$ of the transformer at time interval $t$.

$T_{a}(t)$ is the ambient temperature $\left({ }^{\circ} \mathrm{C}\right)$ at time interval $t$.

$\triangle H S T O G(t)$ is the hot-spot to top-oil gradient $\left({ }^{\circ} \mathrm{C}\right)$ of the transformer at time interval $t$.

$\operatorname{LoL}(24 h r)$ is the transformer loss life (\%) after a 24-hour operating period.

$A A F(t)$ is the aging acceleration factor of the transformer at time interval $t$. $A A F(t)$ has a direct relationship with $H S T(t)$.

$T$ is the total number of time intervals.

$T_{s}$ is the duration of time interval in hours.

$N_{\text {life }}$ is the normal useful life expectancy of the transformer in hours.

Equation (6) limits the transformer loading to 1.8 per unit of its rated capacity. In (7), the top-oil temperature rise is limited to $110^{\circ} \mathrm{C}$ to manage pressure build-up. This is to prevent expansion of oil which could lead to overflow of oil in the tank. The $H S T$ is kept under $140^{\circ} \mathrm{C}$ in (8) to prevent formation of gas bubbles in the oil and paper insulation. Equation (9) ensures that the daily cumulative loss of life of the transformer insulation does not exceed that of normal operation of the transformer at $H S T$ of $110^{\circ} \mathrm{C}$ for 24 hours.

Figure 3 shows the algorithm of the load management.

\section{Case Study}

A distribution transformer serving a real urban residential LV network in Cardiff is the case study. The area is supplied by a $500-\mathrm{kVA}, 11 / 0.415-\mathrm{kV}$ (no load), $50-\mathrm{Hz}$, Dyn11, ONAN mineral oil filled, free breathing, ground mounted transformer. The transformer supplies 347 households consisting of 298 buildings in four feeders. Figure 4 shows the simplified diagram of the LV network and Table 1 gives the analysis of the number of buildings per feeder, annual baseline load of the feeders in the year 2014 and the length of the feeders.

National projection figures for the number of households in GB from [29], [30] and national projection figures of the different uptake scenarios of EVs and HPs as presented in the National Grid's FESs document [31] were scaled down to the level of the LV network. The process of scaling down was well detailed in [32]. National Grid's FESs presents a number of "plausible and credible pathways for the future of energy for GB, from today out to 2050". These scenarios are developed based on the energy trilemma of security, affordability and sustainability [31].

In the FESs, the most optimistic uptake scenario for LCTs in general and EVs and HPs in particular is called the "Two Degrees" (TD). The scenario name "TD" is derived from the Article 2 of the Paris Agreement [33]. It indicates the target of holding the increase in global average temperature to well below $2^{\circ} \mathrm{C}$ above the pre-industrial levels. The TD depicts a scenario of prosperous economic growth, increased focus on renewable energy sources (RESs) and LCTs, and strong political drive to achieve the renewable integration and all of UK's 


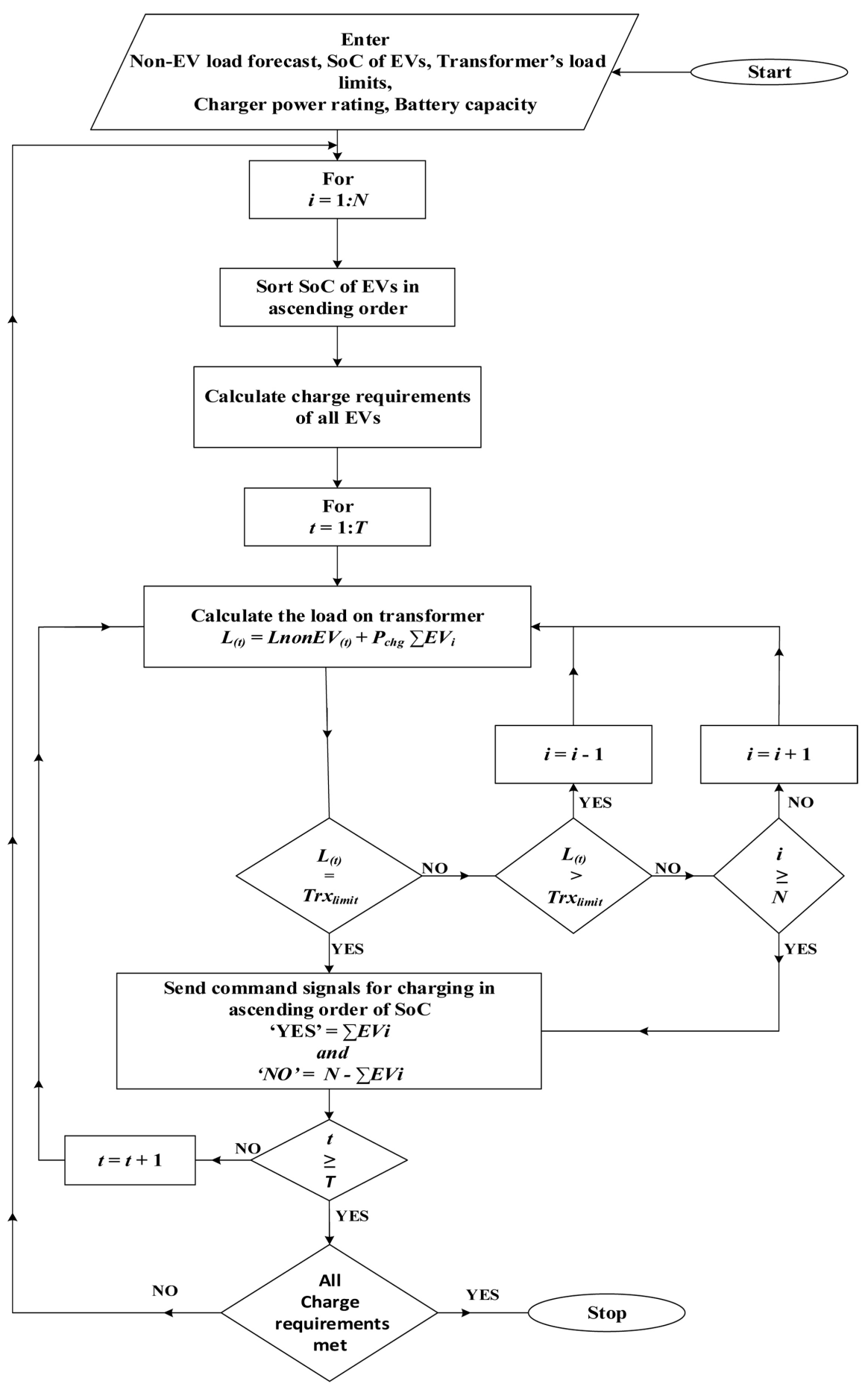

Figure 3. The algorithm of the load management.

2050 emissions reduction targets. It is a scenario in which technology and investment are focused on innovation in RESs (solar and wind) and low carbon (nuclear) generation.

Table 2 presents the number of EVs and HPs the LV network is hosting under the TD scenario in the years 2020, 2030, 2040 and 2050.

By the year 2050, the LV network is hosting 256 EVs and 207 HPs. The EVs 


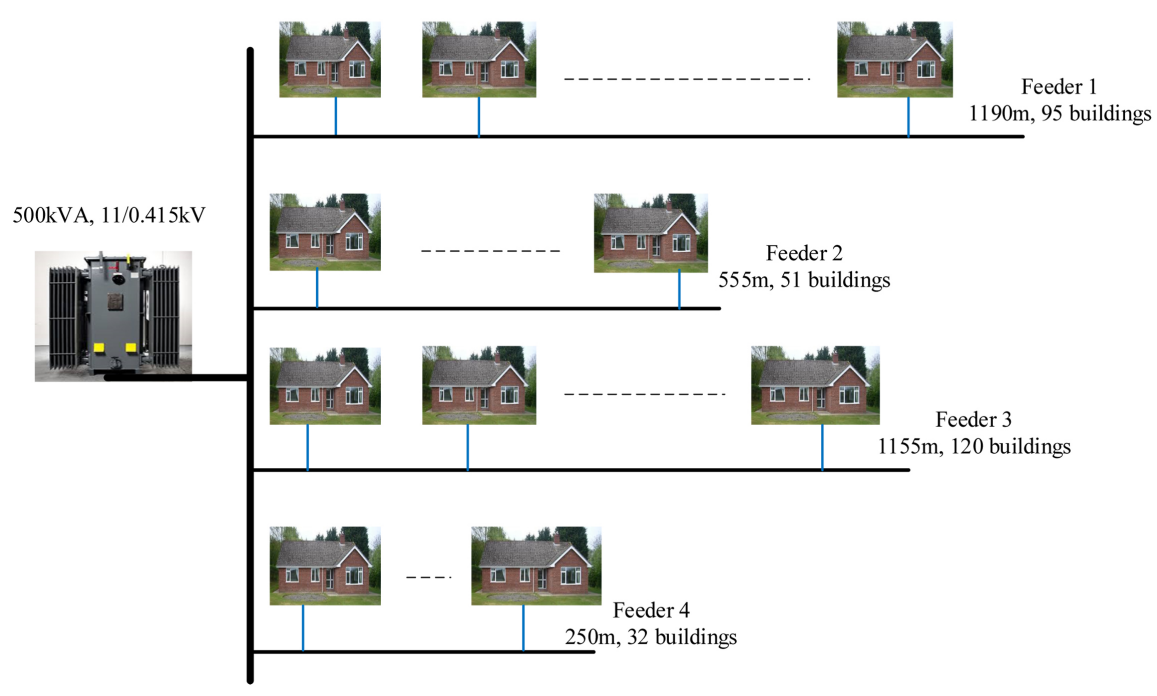

Figure 4. Simplified diagram of the case study LV network.

Table 1. Feeders analysis.

\begin{tabular}{cccc}
\hline Feeder & 2014 Annual load (MWh) & Length (m) & No of Buildings \\
\hline 1 & 360.78 & 1190 & 95 \\
2 & 202.29 & 555 & 51 \\
3 & 402.70 & 1155 & 120 \\
4 & 108.94 & 250 & 32 \\
Total & 1074.71 & & $\mathbf{2 9 8}$ \\
\hline
\end{tabular}

Table 2. Number of EVs and HPs in the LV network under TD scenario, 2020-2050 [31].

\begin{tabular}{cccc}
\hline Year & $\begin{array}{c}\text { Number of } \\
\text { households (Units) }\end{array}$ & $\begin{array}{c}\text { Number of EVs } \\
\text { (Units) }\end{array}$ & $\begin{array}{c}\text { Number of HPs } \\
\text { (Units) }\end{array}$ \\
\hline 2020 & 357 & 23 & 5 \\
2030 & 360 & 93 & 45 \\
2040 & 374 & 167 & 95 \\
2050 & 409 & 256 & 207 \\
\hline
\end{tabular}

and the HPs are distributed amongst the feeders based on the ratio of the number of buildings per feeder.

Future load profile of the LV network for the year 2050 is created considering the baseline load growth and uptake of EVs and HPs by the residents of the area. Based on the normalisation of load profiles from [34], projected annual baseline demand of the LV network for the year 2050 as determined in [32] is converted to half-hourly seasonal (summer weekday and winter weekday) daily profiles. In this research work, residential baseline electricity demand is described as the household electricity demand which excludes the electricity demand of EVs and HPs. 
The EVs daily charge requirements distribution of the LV network as determined in [32] and the half-hourly percent of average daily charge in [35] are adopted to generate the actual EVs average half-hourly charge requirements $(\mathrm{kWh})$ of the LV network. Figure 5 shows the EVs daily charge requirements distribution of the LV network.

From Figure 5, the maximum daily charge requirement of an EV in the LV network is $17 \mathrm{kWh}$. Given the EV battery capacity to be $24 \mathrm{kWh}$, the minimum initial SoC of EV batteries is 30\%. Figure 6 is the average half-hourly EV charging profile (\%). Data such as number of trips, start and end times of trips, average distance travelled, arrival times at homes, etc. generated from the National Travel Survey and Time Use Survey formed the basis of this charging profile [35].

The daily average electricity demand of a 6-kW variable speed air-source HP, shown in Figure 7, whose operating profile for the provision of both residential space heating and hot water was derived from the simulation described in [32] was used in this study.

Powerflow simulation studies of the created future load profiles of the LV network were performed for the year 2050 on a typical winter weekday and a typical summer weekday. GridLAB-D power system simulation software was used

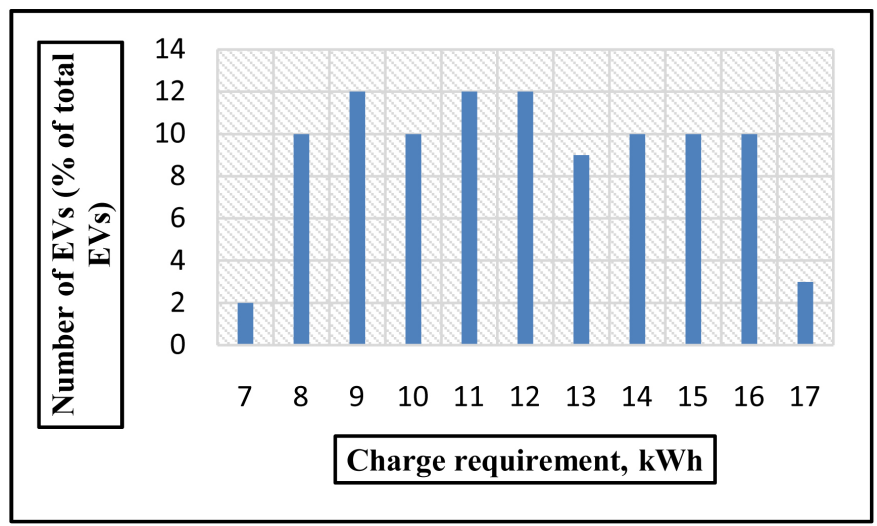

Figure 5. EVs daily charge requirements distribution of the LV network [32].

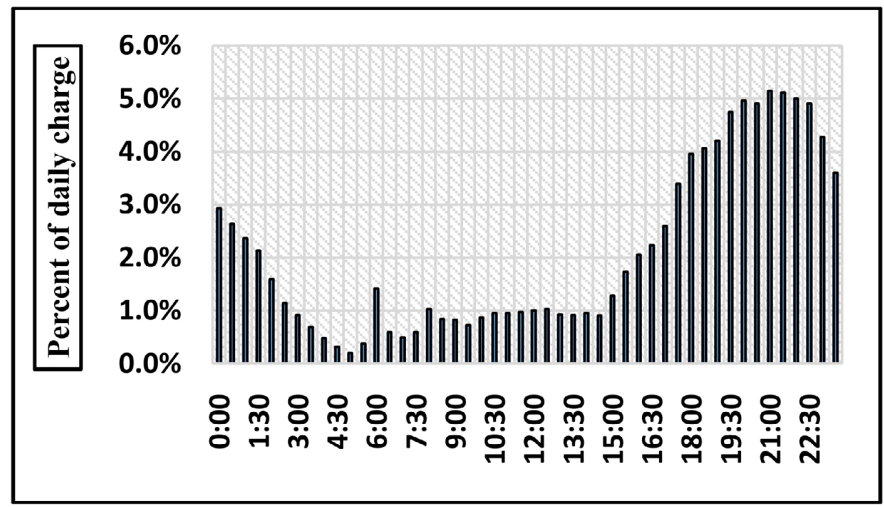

Figure 6. Average half-hourly EV charging profile (\%) [35]. 
for the powerflow simulation study. The powerflow simulation showed the impacts of the load demand of the uptake of EVs and HPs in the LV network on the transformer loading. Figure 8 and Figure 9 show the half-hourly Non-EV and EV load demand of the LV area on a typical winter weekday and a typical summer weekday respectively.

As seen from Figure 8, on a winter weekday in the year 2050, the combined Non-EV and EV load demand of the LV area outstrips both the transformer capacity limit and adaptive thermal limit. But the severity of the overloading condition is much reduced with the transformer adaptive thermal limit relative to its capacity limit. Reasons for the overloading condition on a winter weekday are increased use of HPs (see Figure 7) and increased charging of EVs coinciding with the peak of the non-EV loads (see Figure 6).

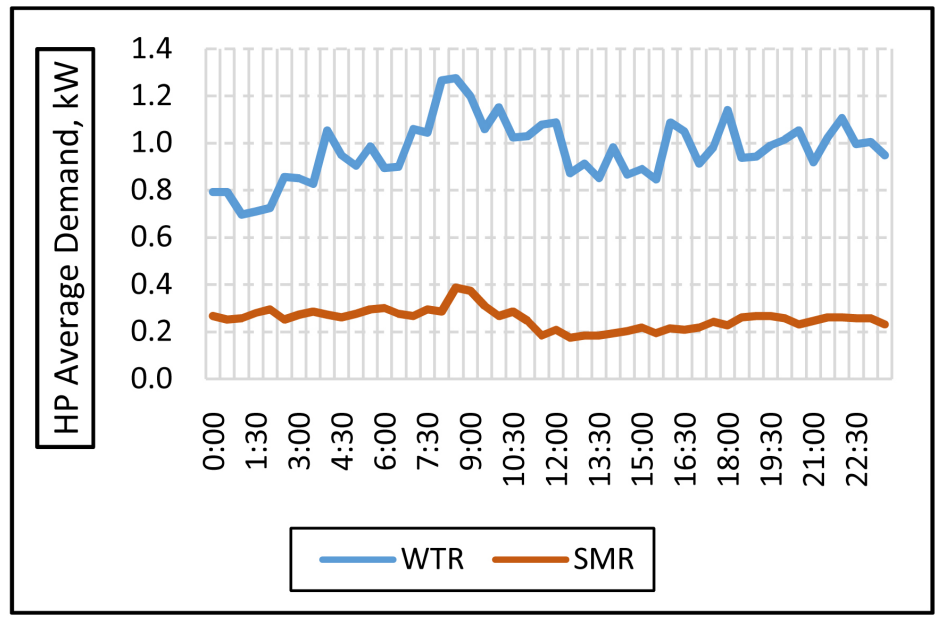

Figure 7. HP daily average demand [32].

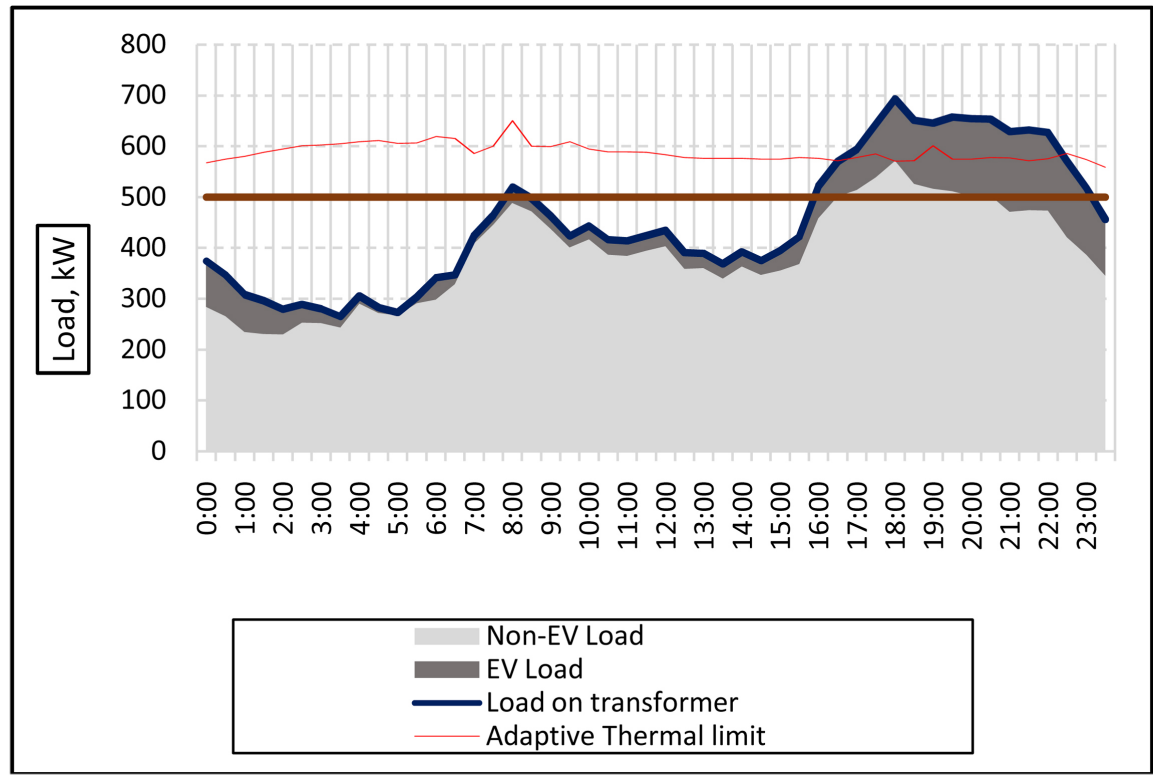

Figure 8. Half-hourly non-EV and EV load demand on a winter weekday in the year 2050. 


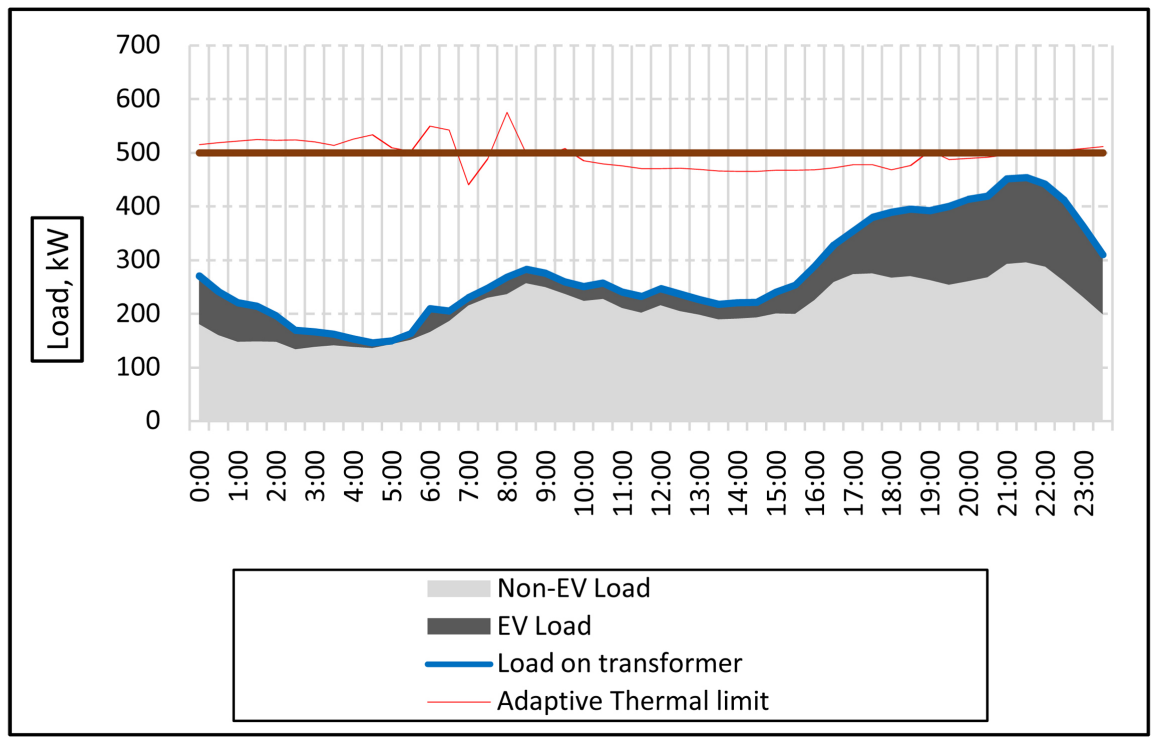

Figure 9. Half-hourly non-EV and EV load demand on a summer weekday in the year 2050 .

\section{Implementation}

The thermal model of the transformer of the LV network is developed according to IEC 60076-7:2005 standard [28]. The parameters of the transformer of the LV distribution network are given in Table 3.

Ambient temperature data for a typical winter day are from the MET Office [36]. Table 4 gives the analysis of the total charge requirements of EVs in the LV area in the year 2050 as estimated from the number of EVs in the LV network in 2050 (see Table 2) and the EVs daily charge requirements distribution of the LV network (see Figure 5).

From Table 4, it is seen that a total charge of $3068 \mathrm{kWh}$ is required and the minimum initial SoC of EVs is $30 \%$. With the assumed constant charging power of $3.7 \mathrm{~kW}$ and battery capacity of $24 \mathrm{kWh}$, a minimum plugging time of 5 hours per EV would be necessary to guarantee all EVs are fully restored to $100 \% \mathrm{SoC}$ considering the minimum initial SoC of $30 \%$.

The optimisation objective function of Equation (1) subject to the constraints of Equations (2) to (9) was solved using "Analytical Solver" commercial optimisation software [37]. The model was diagnosed as "QCP NonCvx" and was solved using the standard GRG Nonlinear Solver Engine. Solution was found in 11.45 seconds at the 9th iteration, with all the constraints and optimality conditions satisfied, on a 3-GHz, 8-GB, 64-bit Windows 10 personal computer.

\section{Results and Discussion}

Figure 10 shows the half-hourly contributions of the Non-EV load and the EV load components to the transformer load of the LV area and the number of EVs that could receive charging at half-hourly interval on a typical winter weekday in the year 2050 after applying the proposed load management technique. The 
Table 3. Distribution transformer parameters.

\begin{tabular}{cc}
\hline Parameters & Values \\
Rating & $11 / 0.4 \mathrm{kV}, 500 \mathrm{kVA}$ \\
Cooling type & ONAN \\
$x$ & 0.8 \\
$y$ & 1.6 \\
$k_{11}$ & 1.0 \\
$k_{21}$ & 1.0 \\
$k_{22}$ & 2.0 \\
$\Delta T O R_{(R)}$ & $65^{\circ} \mathrm{C}$ \\
$\Delta H S T O G_{(R)}$ & $23.0^{\circ} \mathrm{C}$ \\
$N_{l i f e}$ & 180,000 hours \\
$\tau_{o}$ & 180 minutes \\
$\tau_{w}$ & 10 minutes \\
$R$ & 5 \\
Rated load current $\left(L_{r}\right)$ & $722.5 \mathrm{~A}$
\end{tabular}

Table 4. Analysis of daily charge requirements of EVs.

\begin{tabular}{ccccc}
\hline $\begin{array}{c}\text { Number of } \\
\text { EVs (Units) }\end{array}$ & \multicolumn{2}{c}{ Initial SoC } & $\begin{array}{c}\text { Energy required } \\
\text { for charging } \\
(\mathrm{kWh})\end{array}$ & $\begin{array}{c}\text { Minimum } \\
\text { plugging } \\
\text { time (hrs) }\end{array}$ \\
\cline { 2 - 5 } 5 & 70 & 17 & 35 & 1.9 \\
26 & 67 & 16 & 208 & 2.2 \\
30 & 63 & 15 & 270 & 2.4 \\
26 & 58 & 14 & 260 & 2.7 \\
30 & 54 & 13 & 330 & 3.0 \\
30 & 50 & 12 & 360 & 3.2 \\
23 & 46 & 11 & 299 & 3.5 \\
26 & 42 & 10 & 364 & 3.8 \\
26 & 38 & 9 & 390 & 4.1 \\
26 & 33 & 8 & 416 & 4.3 \\
8 & 30 & 7 & 136 & 4.6 \\
Total 256 & & & 3068 & \\
\hline
\end{tabular}

transformer is no more overloaded. Although, the load outstrips the nominal capacity of the transformer, but it is kept within the confines of the transformer adaptive thermal limits. The useful normal life expectancy and therefore, the normal operation of the transformer is not compromised. Between 16:30 hours and 20:30 hours, the Non-EV component of the total load demand exceeds the transformer nominal capacity. 


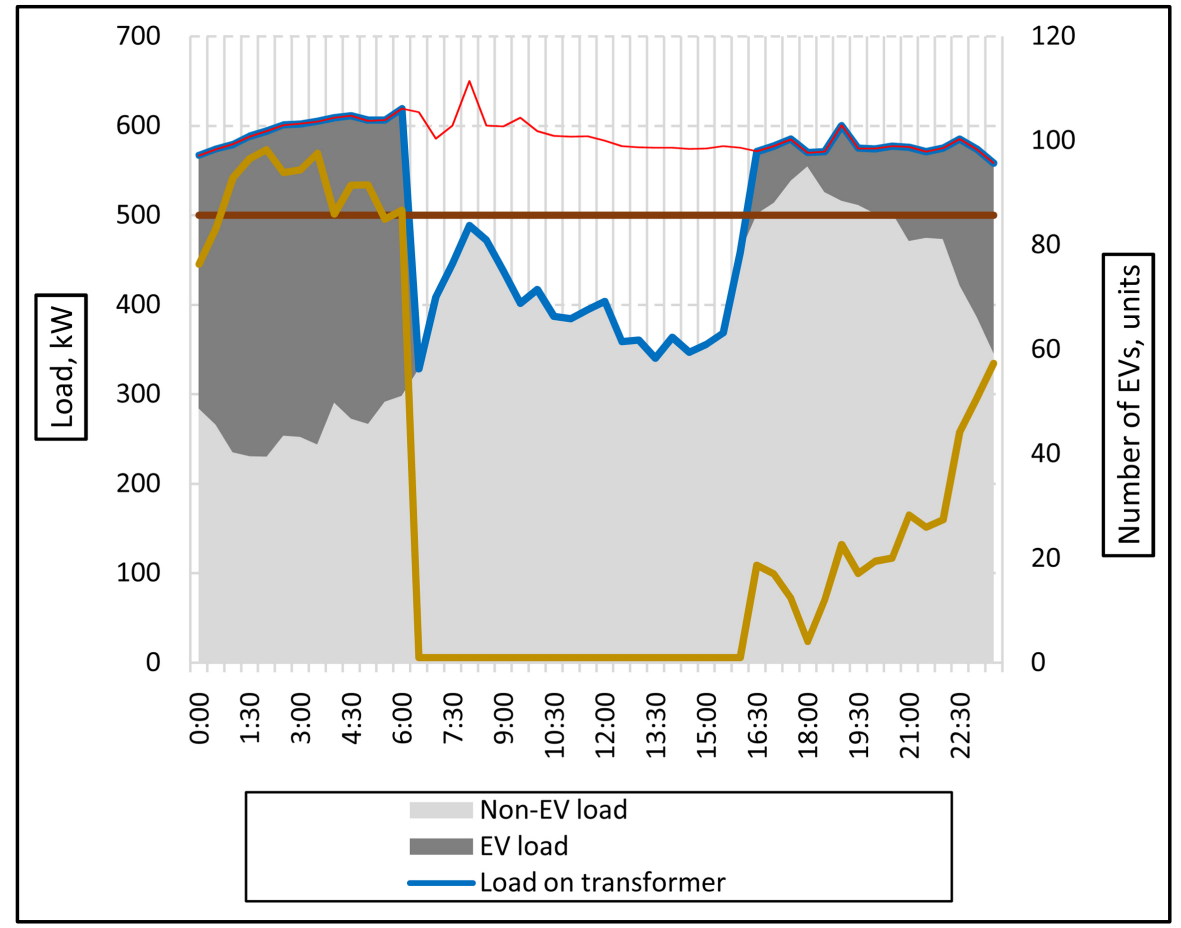

Figure 10. Half-hourly contribution of Non-EV and EV load components to transformer load after applying load management technique.

Therefore, hinging the decision for the need of load management on the transformer nominal capacity would require more complex solution than taking the advantage of the flexibility of the charging of EVs as in the present case. This underscores the importance of why the need for load management and/or transformer capacity reinforcement or otherwise should not be based on static nominal capacity of transformers but rather on their adaptive thermal ratings.

The charging of the EVs is scheduled to avoid the peak of the Non-EV load. At the peak of the Non-EV load, only 4 EVs could receive charging. As the Non-EV load decreases, more EVs are allowed to be charged. At 02:00 hours, as many as $98 \mathrm{EV}$ s could be charged at once.

During the CCR, a total of $5738 \mathrm{kWh}$ of energy is available for EVs charging. This is almost double the daily charge requirements of $3068 \mathrm{kWh}$ of the $256 \mathrm{EVs}$ in the LV area in the year 2050. The valley region of the total load on transformer between 06:00 hours and 16:30 hours is the UCR. During this period, EV owners could charge their vehicles at their own liberty as the possibilities of overloading the transformer are remote.

With the potential of more availability of energy (kWh) for charging of EVs during the CCR and the liberty of charging of EVs during the UCR, the LV area distribution network could accommodate further uptake of EVs up to the year 2050 without immediate need for capacity reinforcement.

\section{Conclusions}

A de-centralised load management technique exploiting the flexibility in the 
charging of EVs was presented. Two charging regimes were assumed. The Controlled Charging Regime between 16:30 hours and 06:00 hours of the next day and the Uncontrolled Charging Regime between 06:00 hours and 16:30 hours of the same day. During the Controlled Charging Regime, it was assumed the charging of EVs is coordinated and controlled by means of a wireless two-way communication link between EV Smart Charge Controllers at EV owners' premises and the EV Load Controller at the local LV substation.

The technique was applied on a typical GB LV area distribution network when its transformer was carrying the future load demand on a typical winter weekday in the year 2050. From the results the following conclusions can be made:

- With good load management technique, LV distribution network could accommodate high uptake of EVs. In the case of this work, a total of $5738 \mathrm{kWh}$ energy was available for charging of EVs during the Controlled Charging Regime. This is almost double the daily charge requirement of $3068 \mathrm{kWh}$ of 256 EVs (representing 63\% uptake) in the LV area.

- Decision to engage in load management or capacity reinforcement should be based on adaptive thermal limit of the transformer rather than on its static capacity limit. In the case of this work, with the capacity limit as the deciding factor for load management, it would require more than the flexibility of EV load to implement because the Non-EV load component alone outstrips the transformer capacity limit.

In the future, as the technology for the bi-directional power flow between grid and EV matures, and costs of EV batteries drop such that bi-directional operation of EV batteries becomes economical from the perspective of EV owners, the concept could be inserted in the present work to extend it further.

\section{Acknowledgements}

Rilwan Oliyide would like to acknowledge the Nigeria Tertiary Education Trust Fund (TETFund) for sponsoring his Ph.D. in Cardiff University. He also would like to appreciate Moshood Abiola Polytechnic (MAPOLY), Abeokuta, Nigeria for the support received during his Ph.D. studies.

\section{Conflicts of Interest}

The authors declare no conflicts of interest regarding the publication of this paper.

\section{References}

[1] Deb, S., Tammi, K. and Mahanta, P. (2018) Impact of Electric Vehicle Charging Station Load on Distribution Network. Energies, 11, 1-25.

https://doi.org/10.3390/en11010178

[2] Haque, A.N.M.M., Nguyen, P.H., Bliek, F.W. and Slootweg, J.G. (2017) Demand Response for Real-Time Congestion Management Incorporating Dynamic Thermal Overloading Cost. Sustainable Energy, Grids and Networks, 10, 65-74. https://doi.org/10.1016/j.segan.2017.03.002 
[3] Hu, J., Saleem, A., You, S., Nordström, L., Lind, M. and Østergaard, J. (2015) A Multi-Agent System for Distribution Grid Congestion Management with Electric Vehicles. Engineering Appications of Artificial Intelligence, 38, 45-58. https://doi.org/10.1016/j.engappai.2014.10.017

[4] Liao, R., Hao, J., Ynag, L. and Grzybowski, S. (2011) Study on Aging Characteristics of Mineral Oil/Natural Ester Mixtures Paper Insulation. Proceedings of the 2011 International Conference on Dielectric Liquids, Trondheim, 26-30 June 2011, 1-4.

[5] Haque, A.N.M.M., Shafiullah, D.S., Nguyen, P.H. and Bliek, F.W. (2016) Real-Time Congestion Management in Active Distribution Network Based on Dynamic Thermal Overloading Cost. Power System Computation Conference, Genova, 20-24 June 2016, 1-7. https://doi.org/10.1109/PSCC.2016.7540985

[6] Shahbazi, B., Savaghebi, M. and Shariati, M. (2010) A Probabilistic Approach for Power Transformer Dynamic Loading Capability Assessment. International Review of Electrical Engineering, 5, 952-960.

[7] Jongen, R., Morshuis, P., Smit, J., Jansen, A. and Gulski, E. (2007) A Statistical Approach to Processing Power Transformer Failure Data. Proceedings of CIRED 19th International Conference on Electricity Distribution, Vienna, 21-24 May 2007, 546.

[8] van der Burgt, J., Vera, S.P., Wille-Haussmann, B., Andersen, A.N. and Tambjerg, L.H. (2015) Grid Impact of Charging Electric Vehicles; Study Cases in Denmark, Germany and the Netherlands. Proceedings of 2015 IEEE Eindhoven PowerTech, Eindhoven, 29 June-2 July 2015, 1-6. https://doi.org/10.1109/PTC.2015.7232234

[9] Carter, S., Williamson, G., King, J., Levi, V. and Mcwilliam, J. (2017) Key Findings of DS2030-A Study into Future GB Distribution Network Operations. CIRED-Open Access Proceedings Journal, 2017, 2390-2393.

https://doi.org/10.1049/oap-cired.2017.0947

[10] Kelly, N., Samuel, A. and Hand, J. (2015) Testing Integrated Electric Vehicle Charging and Domestic Heating Strategies for Future UK Housing. Energy and Buildings, 105, 377-392. https://doi.org/10.1016/j.enbuild.2015.07.044

[11] Dubarry, M., Devie, A. and McKenzie, K. (2017) Durability and Reliability of Electric Vehicle Batteries under Electric Utility Grid Operations: Bidirectional Charging Impact Analysis. Journal of Power Sources, 358, 39-49. https://doi.org/10.1016/j.jpowsour.2017.05.015

[12] Hu, J., Morais, H., Lind, M. and Bindner, H.W. (2016) Multi-Agent Based Modeling for Electric Vehicle Integration in a Distribution Network Operation. Electric Power System Research, 136, 341-351. https://doi.org/10.1016/j.epsr.2016.03.014

[13] Rana, R. and Mishra, S. (2018) Day-Ahead Scheduling of Electric Vehicles for Overloading Management in Active Distribution System via Web-Based Application. IEEE Systems Journal, 13, 3422-3432.

https://doi.org/10.1109/JSYST.2018.2851618

[14] UK Power Networks (2014) Impact of Electric Vehicle and Heat Pump Loads on Network Demand Profiles. Report B2.

https://innovation.ukpowernetworks.co.uk/wp-content/uploads/2019/05/B2-Impact -of-Electric-Vehicles-and-Heat-Pump-Loads-on-Network-Demand-Profiles.pdf

[15] Le Vine, S., Polak, J. and Humphrey, A. (2017) Commuting Trends in England 1988-2015. Department of Transport, London.

[16] Gershuny, J. and Sullivan, O. (2017) United Kingdom Time Use Survey, 2014-2015. UK Data Service.

[17] Rahman, S., Dey, S.K., Bhawmick, B.K. and Das, N.K. (2017) Design and Imple- 
mentation of Real Time Transformer Health Monitoring System Using GSM Technology. Proceedings of International Conference on Electrical, Computer and Communication Engineering (ECCE), Cox's Bazar, 16-18 February 2017, 258-261. https://doi.org/10.1109/ECACE.2017.7912915

[18] Pawar, R.R. and Deosarkar, S.B. (2017) Health Condition Monitoring System for Distribution Transformer Using Internet of Things (IoT). Proceedings of 2017 International Conference on Computing Methodologies and Communication (ICCMC), Erode, 18-19 July 2017, 117-122. https://doi.org/10.1109/ICCMC.2017.8282650

[19] Jalilian, M., et al. (2016) Design and Implementation of the Monitoring and Control Systems for Distribution Transformer by Using GSM Network. International Journal of Electrical Power \& Energy Systems, 74, 36-41. https://doi.org/10.1016/j.ijepes.2015.07.022

[20] Mulla, A., Baviskar, J., Khare, S. and Kazi, F. (2015) The Wireless Technologies for Smart Grid Communication: A Review. Proceedings of 5 th International Conference on Communication Systems and Network Technologies, Gwalior, 4-6 April 2015, 442-447. https://doi.org/10.1109/CSNT.2015.146

[21] Mahmood, A., Javaid, N. and Razzaq, S. (2015) A Review of Wireless Communications for Smart Grid. Renewable and Sustainable Energy Review, 41, 248-260. https://doi.org/10.1016/j.rser.2014.08.036

[22] Yarali, A. and Rahman, S. (2012) Wireless Communication for Smart Grids. Proceedings of the 2 nd International Conference on Advanced Collaborative Networks, Systems and Applications 2012 (COLLA 2012), Venice, 24-29 June 2012, 1-9.

[23] British Standards Institution (2011) BS EN 61851-1:2011 Electric Vehicle Conductive Charging System. General Requirements. London.

[24] British Electrotechnical and Allied Manufacturers Association (BEAMA) (2015) A Guide to Electric Vehicle Infrastructure. London.

[25] Department for Transport (DfT) (2018) Vehicle Licensing Statistics: Annual 2017. Statistical Release.

[26] UK. Nissan Motor Corporation (2017) Range and Charging: 2017 Nissan Leaf Electric Car. https://www.nissan.co.uk/vehicles/new-vehicles/leaf/range-charging.html

[27] Department for Transport (DfT) (2018) Analyses from the National Travel Survey. Statistical Release.

[28] International Electrotechnical Commission (IEC) (2005) IEC 60076-7:2005-Power Transformers Part 7: Loading Guide for Oil-Immersed Power Transformers.

[29] Department for Communities and Local Government (DCLG) (2016) Table 401: Household Projections, United Kingdom, 1961-2039.

[30] Office for National Statistics (ONS) (2017) Families and Households: 2017 Statistical Bulletin: People, Population and Community.

[31] National Grid (2017) Future Energy Scenarios.

[32] Oliyide, R.O. (2019) Load Management of Electric Vehicles and Heat Pumps in Emerging Electricity System. Ph.D. Thesis, Cardiff University, Cardiff.

[33] United Nations Framework Convention on Climate Change (UNFCCC) (2015) Paris Agreement.

[34] UK Energy Research Centre. Electricity User Demand Profile Data. http://data.ukedc.rl.ac.uk/simplebrowse/edc/efficiency/residential/LoadProfile/data

[35] National Grid (2015) Future Energy Scenarios.

[36] UK Met Office. Archive Services-Met Office. 
https://www.metoffice.gov.uk/learning/library/archive/services

[37] Frontline Systems Inc. Analytic Solver ${ }^{\circledast}$ Platform.

https://www.solver.com/analytic-solver\%C2\%AE-platform 